\title{
Upper Gastrointestinal Hemorrhage: Development of the Severity Score
}

\author{
Rangson Chaikitamnuaychok ${ }^{\mathrm{a}}$, Jayanton Patumanond ${ }^{\mathrm{b}, \mathrm{c}}$
}

\begin{abstract}
Background: Emergency endoscopy for every patient with upper gastrointestinal hemorrhage is not possible in many medical centers. Simple guidelines to select patients for emergency endoscopy are lacking. The aim of the present report is to develop a simple scoring system to classify upper gastrointestinal hemorrhage (UGIH) severity based on patient clinical profiles at the emergency departments.
\end{abstract}

Methods: Retrospective data of patients with UGIH in a university affiliated hospital were analyzed. Patients were criterion-classified into 3 severity levels: mild, moderate and severe. Clinical and laboratory information were compared among the 3 groups. Significant parameters were selected as indicators of severity. Coefficients of significant multivariable parameters were transformed into item scores, which added up as individual severity scores. The scores were used to classify patients into 3 urgency levels: non-urgent, urgent and emergent groups. Score-classification and criterion-classification were compared.

Results: Significant parameters in the model were age $\geq 60$ years, pulse rate $\geq 100 / \mathrm{min}$, systolic blood pressure $<100 \mathrm{mmHg}$, hemoglobin $<10 \mathrm{~g} / \mathrm{dL}$, blood urea nitrogen $\geq 35 \mathrm{mg} / \mathrm{dL}$, presence of cirrhosis and hepatic failure. The score ranged from 0 to 27 , and classifying patients into 3 urgency groups: non-urgent (score $<4$, $\mathrm{n}=215,21.2 \%$ ), urgent (score $4-16, \mathrm{n}=677,66.9 \%$ ) and emergent (score $>16, \mathrm{n}=121,11.9 \%)$. The score correctly classified $81.4 \%$ of the patients into their original (criterion-classified) severity groups. Under-estimation (7.5\%) and over-estimation $(11.1 \%)$ were clinically acceptable.

Conclusions: Our UGIH severity scoring system classified pa-

Manuscript accepted for publication December 13, 2012

${ }^{a}$ Department of General Surgery, Kamphaeng Phet Hospital, Kamphaeng Phet, Thailand

${ }^{\mathrm{b}}$ Clinical Epidemiology Unit, Faculty of Medicine, Chiang Mai

University, Chiang Mai, Thailand

${ }^{\mathrm{c} C o r r e s p o n d i n g ~ a u t h o r: ~ J a y a n t o n ~ P a t u m a n o n d, ~ C l i n i c a l ~ E p i d e m i o l o g y ~}$

Unit, Faculty of Medicine, Chiang Mai University, Chiang Mai, 50200,

Thailand. Email: jpatumanond@gmail.com

doi: http://dx.doi.org/10.4021/gr488w tients into 3 urgency groups: non-urgent, urgent and emergent, with clinically acceptable small number of under- and over-estimations. Its discriminative ability and precision should be validated before adopting into clinical practice.

Keywords: Gastrointestinal hemorrhage; Gastrointestinal bleeding; Gastroscopy; Prognostic indicators; Scoring system; Clinical prediction rules

\section{Introduction}

Upper gastrointestinal hemorrhage (UGIH) is a common challenge encountered in emergency medicine departments. Hospital admissions were approximately 300,000 cases per year in the United States [1]. Case fatalities were also as high as $7-10 \%$, with a yearly expenses of 2.5 billion \$US [2].

Endoscopy plays a key role in classifying patients. It is generally suggested that endoscopy should be scheduled within 24 hours after hospital admission [3-6]. The American Society for Gastrointestinal Endoscopy suggested a somewhat earlier timing, within 12 hours [7], but actual early endoscopic examinations were usually scheduled between 2 to 24 hours [8-13]. Almost $80 \%$ of UGIH is self-limited [14]. Therefore in most cases endoscopy could be postponed to the following day. This implies that there are only a fraction of patients who actually required an emergency endoscopy. However, this is possible only in hospitals which are 24-hour well-equipped [15]. Clinicians all agreed that endoscopy for patients with mild and moderate UGIH could practically be delayed, and that emergency endoscopy is necessary only for some patients with severe bleeding or those who are in a state of shock. Existing screening procedures for patients with UGIH were mostly based on a scoring system that stratifies patients into those with high or low risk, focusing on ultimate clinical outcomes such as re-bleeding and/or death [16-18]. The purpose of such screening was mainly to help clinicians discharge patients with low risk early and safely, to be treated as out-patients, and to selectively admit patients with high risk to an intensive care unit for close monitoring [16-18]. 
Table 1. Characteristics of Patients With Upper Gastrointestinal Hemorrhage, Criterion-Classified into Three Severity Levels

\begin{tabular}{|c|c|c|c|c|}
\hline \multirow[b]{2}{*}{ Patient characteristics } & Mild & Moderate & Severe & \multirow[b]{2}{*}{ P-value } \\
\hline & $\begin{array}{l}n=255 \\
\text { mean } \pm S D\end{array}$ & $\begin{array}{l}n=664 \\
\text { mean } \pm S D\end{array}$ & $\begin{array}{l}n=124 \\
\text { mean } \pm S D\end{array}$ & \\
\hline \multicolumn{5}{|l|}{ Demographics } \\
\hline Male (n, \%) & $175(68.6)$ & $427(64.3)$ & $87(70.2)$ & 0.871 \\
\hline Age (year) & $54.6 \pm 18.0$ & $60.4 \pm 14.8$ & $58.4 \pm 14.2$ & 0.010 \\
\hline \multicolumn{5}{|l|}{ Mode of presentation (n, \%) } \\
\hline Hematemesis & $117(45.9)$ & $299(45.0)$ & $66(53.2)$ & 0.315 \\
\hline Coffee ground vomiting & $67(26.3)$ & $114(17.2)$ & $26(21.0)$ & 0.048 \\
\hline Hematochezia & $20(7.8)$ & $40(6.0)$ & $8(6.5)$ & 0.462 \\
\hline Melena & $113(44.3)$ & $421(63.4)$ & $69(55.7)$ & 0.001 \\
\hline Syncope & $28(11.0)$ & $144(21.7)$ & $34(27.4)$ & $<0.001$ \\
\hline \multicolumn{5}{|l|}{ Hemodynamics } \\
\hline Pulse (/min) & $89.8 \pm 16.3$ & $91.4 \pm 15.7$ & $93.1 \pm 17.7$ & 0.022 \\
\hline $\mathrm{SBP}(\mathrm{mmHg})$ & $128.6 \pm 21.6$ & $120.6 \pm 20.5$ & $88.5 \pm 17.0$ & $<0.001$ \\
\hline \multicolumn{5}{|l|}{ Biochemicals } \\
\hline Hemoglobin (g/dL) & $11.4 \pm 2.4$ & $7.0 \pm 2.1$ & $7.4 \pm 2.9$ & $<0.001$ \\
\hline BUN (mg/dL) & $23.9 \pm 16.5$ & $36.5 \pm 21.7$ & $37.6 \pm 22.5$ & $<0.001$ \\
\hline \multicolumn{5}{|l|}{ Co-morbidities (n, \%) } \\
\hline Cirrhosis & $14(5.5)$ & $106(16.0)$ & $28(22.6)$ & $<0.001$ \\
\hline Hepatic failure & $0(0)$ & $6(0.9)$ & $2(1.6)$ & 0.071 \\
\hline Cardiac failure & $1(0.4)$ & $6(0.9)$ & $4(3.2)$ & 0.024 \\
\hline Renal failure & $4(1.6)$ & $53(8.0)$ & $12(9.7)$ & $<0.001$ \\
\hline \multicolumn{5}{|l|}{ Clinical outcomes (n, \%) } \\
\hline Re-bleeding & $6(2.4)$ & $42(6.3)$ & $18(14.5)$ & $<0.001$ \\
\hline Dead & $0(0)$ & $1(0.2)$ & 24 (19.4) & $<0.001$ \\
\hline
\end{tabular}

${ }^{*} \mathrm{P}$-value from chi-squared for linear trends, or two-way ANOVA by rank. SD: standard deviation; SBP: systolic blood pressure; BUN: blood urea nitrogen.

Our study focused on developing a simple scoring system to predict UGIH severity, by using patient clinical profiles on arrival at the emergency departments, as had been reported earlier [19]. The scores may be used to identify and discriminate UGIH patients with different severity levels without depending entirely on endoscopic examinations and findings.

\section{Materials and Methods}

\section{Patients and methods}

The study was conducted in Kamphaeng Phet Hospital, a university-affiliated tertiary hospital in the northern region of Thailand. We retrieved medical files of patients who present- 
Table 2. Significant Predictors of Upper Gastrointestinal Hemorrhage Severity and Assigned Item Score

\begin{tabular}{|c|c|c|c|c|c|c|}
\hline Predictors & Category & OR & $95 \% \mathrm{CI}$ & P-value & Coefficient* & Score \\
\hline \multirow[t]{2}{*}{ Age (year) } & $\geq 60$ & 1.57 & $1.13-2.18$ & 0.007 & 0.45 & 1 \\
\hline & $<60$ & 1.00 & ref & & & 0 \\
\hline \multirow[t]{2}{*}{ Pulse (/min) } & $\geq 100$ & 1.56 & $1.11-2.19$ & 0.011 & 0.44 & 1 \\
\hline & $<100$ & 1.00 & ref & & & 0 \\
\hline \multirow[t]{2}{*}{ Systolic pressure $(\mathrm{mmHg})$} & $<100$ & 97.49 & $54.86-173.25$ & $<0.001$ & 4.58 & 10.5 \\
\hline & $\geq 100$ & 1.00 & ref & & & 0 \\
\hline \multirow[t]{2}{*}{ Hemoglobin (g/dL) } & $<10$ & 15.00 & $10.48-21.46$ & $<0.001$ & 2.71 & 6 \\
\hline & $\geq 10$ & 1.00 & ref & & & 0 \\
\hline \multirow[t]{2}{*}{ BUN (mg/dL) } & $\geq 35$ & 2.22 & $1.57-3.14$ & $<0.001$ & 0.80 & 2 \\
\hline & $<35$ & 1.00 & Ref & & & 0 \\
\hline \multirow[t]{2}{*}{ Cirrhosis } & yes & 2.55 & $1.58-4.14$ & $<0.001$ & 0.94 & 2 \\
\hline & no & 1.00 & Ref & & & 0 \\
\hline \multirow[t]{2}{*}{ Hepatic failure } & yes & 8.12 & $1.66-39.67$ & 0.010 & 2.09 & 4.5 \\
\hline & no & 1.00 & ref & & & 0 \\
\hline
\end{tabular}

${ }^{*}$ Coefficients from multivariable continuation ratio logistic regression. OR: odds ratio; Cl: confidence interval; ref: reference category; BUN: blood urea nitrogen.

ed to the emergency department with upper gastrointestinal bleeding, between 2009 and 2010. The ICD10 keywords for hospital database search were: K920-Hematemesis, K921Melena and K922-Gastrointestinal hemorrhage unspecified.

\section{Indicator parameters}

The patient profiles of interest were: 1) Demographic profiles: gender and age; 2) Mode of presentation: hematemesis, coffee ground vomiting, hematochezia, melena, and syncope; 3) Hemodynamic profiles: pulse rate and systolic blood pressure; 4) Biochemical profiles: hemoglobin and blood urea nitrogen, and 5) Co-morbidities: presence of cirrhosis, hepatic failure, cardiac failure and renal failure.

\section{Definitions of UGIH severity: an outcome of interest}

We used the following criteria to define UGIH severity: 1) Severe: patients who required surgical interventions to stop bleeding, patients in a state of grade 3 and 4 shock [20], and patients who did not survive; 2) Moderate: patients who required endoscopy to stop bleeding (endotherapy), patients with re-bleeding, patients in a state of grade 1 and 2 shock, and patients who required blood transfusion; 3) Mild: patients with no signs of shock, patients who required endos- copy without hemostasis, and patients who did not required any blood transfusions.

\section{Data analysis}

The patient profiles were compared across the three severity groups by chi-squared tests for linear trends, or two-way ANOVA by rank. Significant indicators for UGIH severity were presented by odds ratios from a multivariable ordinal continuation ratio logistic regression, which is most suitable for ordinal-natured outcomes such as in this study. The significant coefficients were transformed into item scores and added up to a single total score for each patient. The discriminative performances of the scores were displayed graphically. The patients were classified by the scores into 3 urgency groups corresponding to their original severity: non-urgent, urgent and emergent. The score-classification of urgency was compared to the criterion-classification of severity.

The study was approved by The Kamphaeng Phet Hospital Ethical Committee for Clinical Research. No patients inform consents were required for this retrospective data collection. Traceable patient information was omitted in all processes of data analysis and presentations. The authors declared no out-source grants received and no conflicts of interests. 
Table 3. Score-Classified Urgency Levels, Criterion-Classified Severity Levels, and Risk Estimation Validity

\begin{tabular}{|c|c|c|c|c|c|c|c|c|}
\hline \multirow{2}{*}{\multicolumn{2}{|c|}{$\begin{array}{l}\text { Score-classified } \\
\text { urgency levels }\end{array}$}} & \multirow{2}{*}{$\begin{array}{l}\text { Score } \\
\text { range }\end{array}$} & \multicolumn{3}{|c|}{ Criterion-classified severity levels } & \multicolumn{3}{|c|}{ Risk estimation validity* } \\
\hline & & & $\begin{array}{l}\text { Mild } \\
\text { n }=247\end{array}$ & $\begin{array}{l}\text { Moderate } \\
n=650\end{array}$ & $\begin{array}{l}\text { Severe } \\
n=116\end{array}$ & $\begin{array}{l}\text { Over } \\
(\%)\end{array}$ & $\begin{array}{l}\text { Correct } \\
(\%)\end{array}$ & $\begin{array}{l}\text { Under } \\
(\%)\end{array}$ \\
\hline Mean \pm SD & & & $3.0 \pm 3.5$ & $8.3 \pm 3.3$ & $16.1 \pm 4.2$ & & & \\
\hline $\mathrm{IQR}^{* *}$ & & & $0-6$ & $7-9$ & $13.5-19.5$ & & & \\
\hline Non-urgent & $\mathrm{n}=215$ & $<4$ & 174 & 39 & 2 & - & 17.2 & 4.0 \\
\hline Urgent & $\mathrm{n}=677$ & $4-16$ & 71 & 571 & 35 & 7.0 & 56.4 & 3.5 \\
\hline \multirow[t]{2}{*}{ Emergent } & $\mathrm{n}=121$ & $>16$ & 2 & 40 & 79 & 4.1 & 7.8 & - \\
\hline & & & & & Total & 11.1 & 81.4 & 7.5 \\
\hline
\end{tabular}

${ }^{*}$ Percentage of total patients. SD: standard deviation; IQR: Inter-quartile range.

\section{Results}

We retrieved 1,043 medical files corresponding with the above definitions. Among these, 255 were criterion-classified as mild, 664 as moderate, and 124 as severe.

\section{Significant predictors}

By a univariable analysis, patients in the 3 severity groups were similar according to gender $(\mathrm{P}=0.871)$, presence of hematemesis $(\mathrm{P}=0.315)$, hematochezia $(\mathrm{P}=0.462)$, and hepatic failure $(\mathrm{P}=0.071)$, but were different according to age, coffee ground vomiting, melena, syncope, pulse rate, systolic blood pressure, hemoglobin, blood urea nitrogen, presence of cirrhosis, cardiac failure, and renal failure (Table 1).

Under a multivariable analysis, the remaining patient profiles that significantly increased UGIH severity levels were: age $\geq 60$ years $(\mathrm{OR}=1.57,95 \% \mathrm{CI}=1.13-2.18, \mathrm{P}$ $=0.007)$, pulse rate $\geq 100 / \mathrm{min}(\mathrm{OR}=1.56,95 \% \mathrm{CI}=1.11-$ $2.19, \mathrm{P}=0.011)$, systolic blood pressure $<100 \mathrm{mmHg}(\mathrm{OR}$ $=97.49,95 \% \mathrm{CI}=54.86-173.25, \mathrm{P}<0.001)$, hemoglobin $<10 \mathrm{~g} / \mathrm{dL}(\mathrm{OR}=15.00,95 \% \mathrm{CI}=10.48-21.46, \mathrm{P}<$ $0.001)$, blood urea nitrogen $\geq 35 \mathrm{mg} / \mathrm{dL}(\mathrm{OR}=2.22,95 \% \mathrm{CI}$ $=1.57-3.14, \mathrm{P}<0.001)$, presence of cirrhosis $(\mathrm{OR}=2.55$,

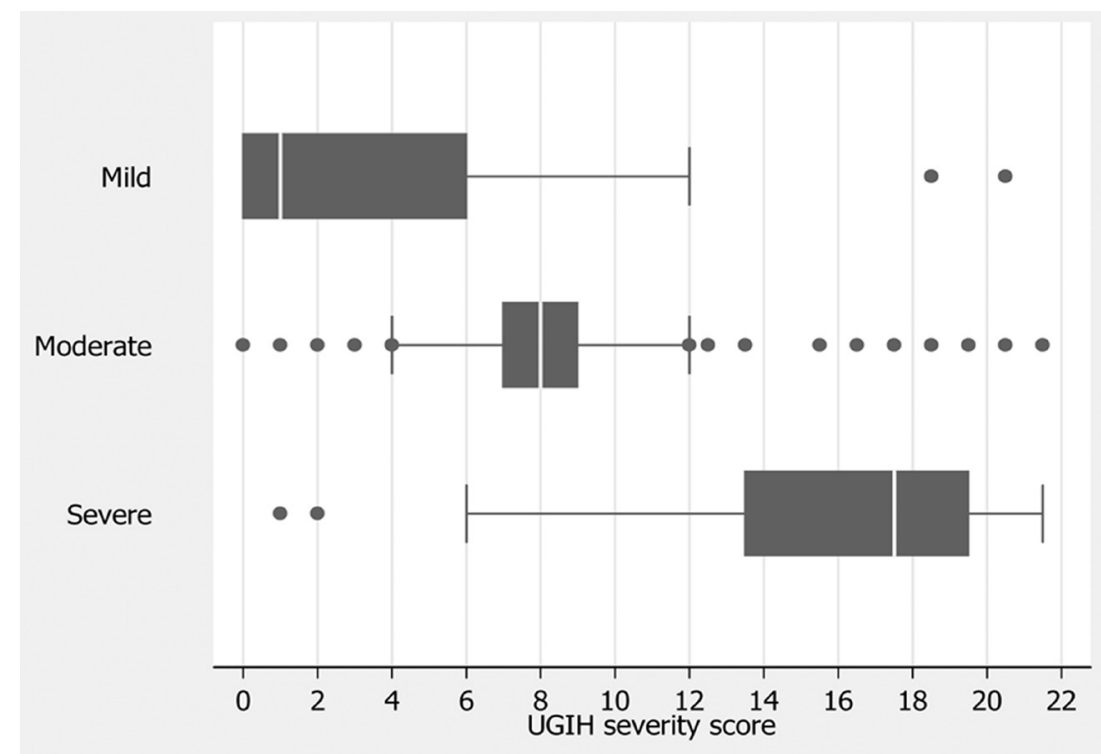

Figure 1. Distribution of UGIH severity scores by criterion-classified severity levels. Vertical lines in box represent medians. Box boundaries represent 25 th and 75 th percentiles. 


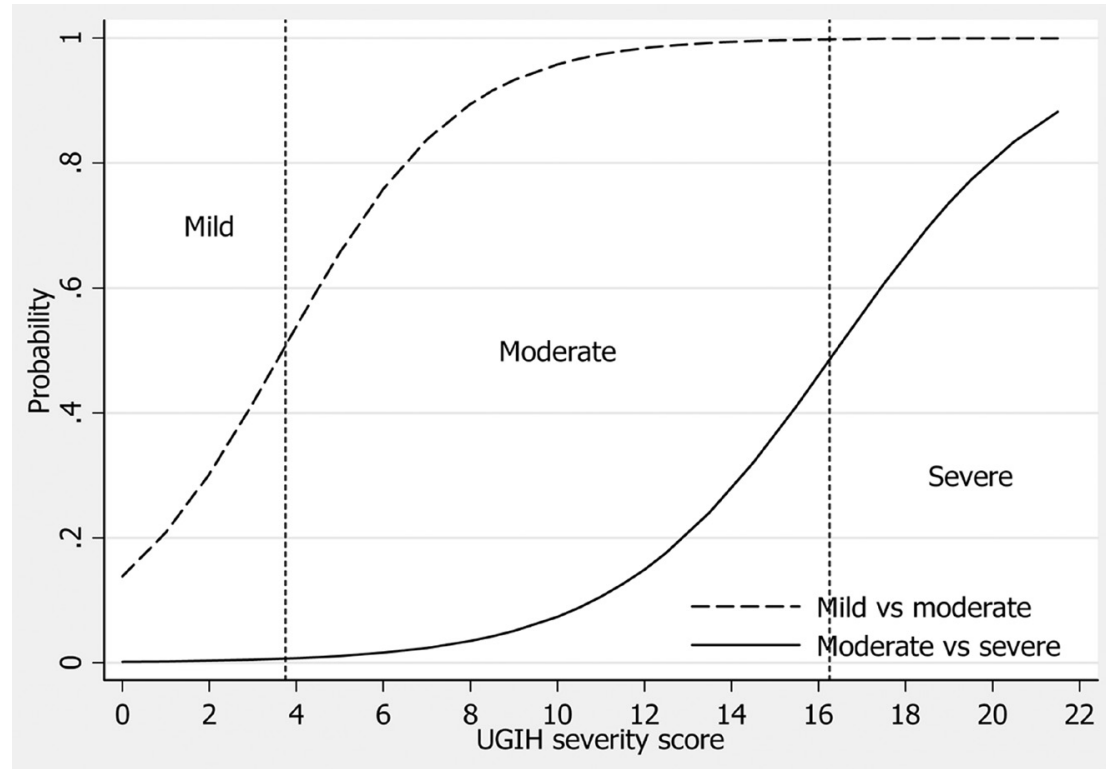

Figure 2. Discrimination of urgency based on UGIH severity scores. Dash line: mild (non-urgent) vs. moderate (urgent). Solid line: moderate (urgent) vs. severe (emergent). Vertical dotted lines represent boundaries (cut-off points) of the scores.

$95 \% \mathrm{CI}=1.58-4.14, \mathrm{P}<0.001)$ and presence of hepatic failure $(\mathrm{OR}=8.12,95 \% \mathrm{CI}=1.66-39.67, \mathrm{P}=0.010)$. The first two strongest predictors were systolic blood pressure $<$ $100 \mathrm{mmHg}(\mathrm{OR}=97.49)$ and hemoglobin $<10 \mathrm{~g} / \mathrm{dL}(\mathrm{OR}=$ 15.00) (Table 2).

\section{The scoring system}

The above significant coefficients were divided by the smallest coefficient (0.44) and rounded up or down to the nearest 0.5 integers to serve as item scores. Scores were not available for 30 patients with missing information of key variables. The item scores ranged from 0 to 10.5 and the sum (total) scores may range from 0 to 27 (Table 2).

\section{Discriminations}

The mean scores for patients in the mild, moderate and severe groups were $3.0 \pm 3.5,8.3 \pm 3.3$, and $16.1 \pm 4.2$ respectively (Table 3), and clustered within different distributions (Fig. 1). The derived scores discriminated moderate UGIH from mild UGIH at moderate scores, and discriminated severe UGIH from moderate UGIH at higher scores (Fig. 2).

\section{Calibrations}

For each of the 3 levels of severity, the score-predicted percents were calibrated against the criterion-classified percents. The compared percentages agreed correspondingly, yielding P-values (goodness-of-fit statistics) of 0.992, 0.996 and 0.992 for prediction of mild, moderate and severe UGIH respectively, implying no lack-of-fits.

\section{Clinical predictions}

The score predicted patients who were at least in a moderate group (moderate or severe vs. mild) with high percentage (area under the ROC curve $=0.8813 ; 95 \%$ CI $=0.8600$ 0.9008 , data not shown), and predict patients who were in a severe (severe vs. mild or moderate) group with greater proportion (area under the $\mathrm{ROC}=0.9274 ; 95 \% \mathrm{CI}=0.9092$ - 0.9422, data not shown).

For clinical purposes, patients were score-classified into 3 groups: scores $<4$, non-urgent; scores $4-16$, urgent; and scores $>16$, emergent. The scores of $<4$ correctly classified 174 out of 247 "mild" patients as "non-urgent", with 1-level under-estimation in 39 patients and 2-level under-estimation in 2 patients (an overall under-estimation of $4.0 \%$ ). A score of 4 - 16 correctly classified 571 out of 650 "moderate" patients as "urgent", with 35 cases (3.5\%) under-estimation and 71 cases $(7.0 \%)$ over-estimation. A score of $>16$ classified 79 out of 116 "severe" patients as "emergent", with 40 patients 1-level over-estimation, and 2 patients 2-level overestimation (an overall over-estimation of 4.1\%) (Table 3).

\section{Discussion}

The development of scoring systems for screening patients presenting with UGIH may be classified into 2 groups. The first group used information on clinical and laboratory parameters without endoscopic findings. Examples are the Blatchford Score [21], the Bleed Risk Classification [22, 23], and the Clinical Rockall Score. The second group used endoscopic examinations in addition to clinical and labora- 
tory parameters. Examples are the Complete Rockall Score, the Baylor-College Score [24] and the Cedars-Sinai Score [25]. Advantages or disadvantages of the two scoring systems depend on the patient settings and clinical outcomes to be predicted. The Blatchford Score has high sensitivity in predicting the need for intervention, but its low specificity results in obvious overestimation [26]. The Rockall Score has a good prediction for death, but a poor prediction for rebleeding, or the need for surgical procedures [27].

The existing scoring systems to classify UGIH patients into severity levels, like the Blatchford Score [21] or the Rockall Score, classified patients into only 2 groups, high risk and low risk. Very narrow ranges of the scores seemed to cause some limitations on clinical practice. In the Blatchford Score, patients scoring 0 were classified as the "low risk" [21, 28 ], and those scoring 1 or more as the "high risk". The same rule was also used in the Rockall Score [28, 29]. As there are only a small number of patients in the low risk group, the score classified a large number of patients as "high risk". For examples, using the Blatchford Score, there would be $92.1 \%$ of patients classified as the "high risk", $81.6 \%$ from using the Clinical Rockall Score, and $70.1 \%$ by using the Complete Rockall Score [28]. This over classification will results in increasing patient loads and medical resources overuse.

Classifying patients into broader ranges may be more practical for clinicians and surgeons. Our study used 2 cut-off points to classify patients into 3 groups: non-urgent, urgent and emergent. Directive actions are correspondingly suggested as follows: 1) Patients scoring $<4$, the "non-urgent" representing "mild" group, had low level of severity. They could be managed conservatively. No blood transfusion may be needed, and elective endoscopy may be appointed in 96 hours to 10 days. These patients may be treated as out-patients. This low risk group correspond to the "low risk" scoring 0 in the Blatchford Score and the Pre-Endoscopic Rockall Score, in which patients were successfully treated as out-patients, the re-bleeding rate was very low and no deaths reported [5, 22]; 2) Patients scoring between 4 and 16, the "urgent" representing the "moderate" group, had a higher severity level. These patients should be admitted to hospital with additional interventions. Resuscitation may be needed. Fluid replacement and/or blood transfusion may be given as indicated. Endoscopy should be appointed within 24 - 96 hours after admission. Patients in this group comprised approximately $60 \%$ of all UGIH patients and corresponded to some patients in the high risk group from the Blatchford Score and the Rockall Score $[5,22]$; 3) Patients scoring > 16, the "emergent" representing the "severe" group, had the highest severity level. These patients may experience blood pressure drop. Vigorous resuscitation may be needed. They should be admitted to an intensive care unit (ICU) for close monitoring. Endoscopy should be appointed immediately, within 24 hours, or as soon as vital signs are stable. Some patients may require surgical interventions to stop bleeding or for life savings. These patients corre- sponded to the "high risk" group in both the Blatchford Score and the Rockall Score.

Our algorithm classified $21.2 \%$ patients as the mild group, similar percentages to the Blatchford Score and the Rockall Score [22], but the number of patients in the high risk group would be diminished from $75-80 \%$ by the Blatchford Score [30] and the Rockall Score to only $11.9 \%$. The rest of the patients would be classified as "moderate" or "urgent" group instead (66.9\%). This algorithm will cut down the number of patients requiring immediate endoscopy $(<24$ hours) to those who were actually severe. The unnecessary cost of care, both medical personnel, medical instruments, and other medical resources for mild and moderate patients could vastly be reduced.

Our scoring system relied on similar clinical and laboratory parameters, without using endoscopic findings, as the Blatchford Score [21] and the Clinical Rockall Score [5]. It should therefore be usable in many settings where endoscopy is unavailable. Primary or secondary care settings may use this scoring system to selectively transfer "severe" patients to the nearest tertiary care settings. Like other scoring systems developed, our score also need external validation to confirm its discriminative ability and precision.

\section{Conclusions}

Patient profiles might be combined to develop a simple UGIH severity scoring system, which could classify patients into non-urgent, urgent and emergent groups. Small numbers of under- and over-estimations were clinically acceptable. However, its discriminative ability and precision should be validated with a new group of similar patients.

\section{Acknowledgement}

The authors wish to thank Kamchai Rangsimanpaiboon, the director of Kamphaeng Phet Hospital for his strong support.

\section{Ethical Approval}

The study was approved by The Kamphaeng Phet Hospital Ethical Committee for Clinical Research.

\section{Conflicts of Interests}

None declared.

\section{References}

1. Yavorski RT, Wong RK, Maydonovitch C, Battin LS, 
Furnia A, Amundson DE. Analysis of 3,294 cases of upper gastrointestinal bleeding in military medical facilities. Am J Gastroenterol. 1995;90(4):568-573.

2. Gilbert DA. Epidemiology of upper gastrointestinal bleeding. Gastrointest Endosc. 1990;36(5 Suppl):S8-13.

3. Barkun A, Bardou M, Marshall JK. Consensus recommendations for managing patients with nonvariceal upper gastrointestinal bleeding. Ann Intern Med. 2003;139(10):843-857.

4. Adler DG, Leighton JA, Davila RE, Hirota WK, Jacobson BC, Qureshi WA, Rajan E, et al. ASGE guideline: The role of endoscopy in acute non-variceal upper-GI hemorrhage. Gastrointest Endosc. 2004;60(4):497-504.

5. Rockall TA, Logan RF, Devlin HB, Northfield TC. Selection of patients for early discharge or outpatient care after acute upper gastrointestinal haemorrhage. National Audit of Acute Upper Gastrointestinal Haemorrhage. Lancet. 1996;347(9009):1138-1140.

6. Eisen GM, Dominitz JA, Faigel DO, Goldstein JL, Kalloo AN, Petersen BT, Raddawi HM, et al. An annotated algorithmic approach to upper gastrointestinal bleeding. Gastrointest Endosc. 2001;53(7):853-858.

7. Gilbert DA, Silverstein FE, Tedesco FJ, Buenger NK, Persing J. The national ASGE survey on upper gastrointestinal bleeding. III. Endoscopy in upper gastrointestinal bleeding. Gastrointest Endosc. 1981;27(2):94-102.

8. Hsu PI, Lin XZ, Chan SH, Lin CY, Chang TT, Shin JS, Hsu LY, et al. Bleeding peptic ulcer--risk factors for rebleeding and sequential changes in endoscopic findings. Gut. 1994;35(6):746-749.

9. Cipolletta L, Bianco MA, Rotondano G, Marmo R, Piscopo R. Outpatient management for low-risk nonvariceal upper GI bleeding: a randomized controlled trial. Gastrointest Endosc. 2002;55(1):1-5.

10. Lin HJ, Wang K, Perng CL, Chua RT, Lee FY, Lee CH, Lee SD. Early or delayed endoscopy for patients with peptic ulcer bleeding. A prospective randomized study. J Clin Gastroenterol. 1996;22(4):267-271.

11. Lee JG, Turnipseed S, Romano PS, Vigil H, Azari R, Melnikoff N, Hsu R, et al. Endoscopy-based triage significantly reduces hospitalization rates and costs of treating upper GI bleeding: a randomized controlled trial. Gastrointest Endosc. 1999;50(6):755-761.

12. Cooper GS, Chak A, Connors AF, Jr., Harper DL, Rosenthal GE. The effectiveness of early endoscopy for upper gastrointestinal hemorrhage: a community-based analysis. Med Care. 1998;36(4):462-474.

13. Chak A, Cooper GS, Lloyd LE, Kolz CS, Barnhart BA, Wong RC. Effectiveness of endoscopy in patients admitted to the intensive care unit with upper GI hemorrhage. Gastrointest Endosc. 2001;53(1):6-13.

14. British Society of Gastroenterology Endoscopy Committee. Non-variceal upper gastrointestinal haemorrhage: guidelines. Gut. 2002;51 Suppl 4:iv1-iv6.
15. Corley DA, Stefan AM, Wolf M, Cook EF, Lee TH. Early indicators of prognosis in upper gastrointestinal hemorrhage. Am J Gastroenterol. 1998;93(3):336-340.

16. Vreeburg EM, Terwee CB, Snel P, Rauws EA, Bartelsman JF, Meulen JH, Tytgat GN. Validation of the Rockall risk scoring system in upper gastrointestinal bleeding. Gut. 1999;44(3):331-335.

17. Saeed ZA, Ramirez FC, Hepps KS, Cole RA, Graham DY. Prospective validation of the Baylor bleeding score for predicting the likelihood of rebleeding after endoscopic hemostasis of peptic ulcers. Gastrointest Endosc. 1995;41(6):561-565.

18. Rockall TA, Logan RF, Devlin HB, Northfield TC. Risk assessment after acute upper gastrointestinal haemorrhage. Gut. 1996;38(3):316-321.

19. Chaikitamnuaychok R, Patumanond J. Clinical risk characteristics of upper gastrointestinal hemorrhage severity: a multivariable risk analysis. Gastroenterol Res. 2012;5(4):149-155.

20. Committee on Trauma, American College of Surgeons. ATLS: Advanced trauma life support program for doctors. 8th ed. Chicago: American College of Surgeons, 2008.

21. Blatchford O, Murray WR, Blatchford M. A risk score to predict need for treatment for upper-gastrointestinal haemorrhage. Lancet. 2000;356(9238):1318-1321.

22. Stanley AJ, Ashley D, Dalton HR, Mowat C, Gaya DR, Thompson E, Warshow U, et al. Outpatient management of patients with low-risk upper-gastrointestinal haemorrhage: multicentre validation and prospective evaluation. Lancet. 2009;373(9657):42-47.

23. Kollef MH, O'Brien JD, Zuckerman GR, Shannon W. BLEED: a classification tool to predict outcomes in patients with acute upper and lower gastrointestinal hemorrhage. Crit Care Med. 1997;25(7):1125-1132.

24. Saeed ZA, Winchester CB, Michaletz PA, Woods KL, Graham DY. A scoring system to predict rebleeding after endoscopic therapy of nonvariceal upper gastrointestinal hemorrhage, with a comparison of heat probe and ethanol injection. Am J Gastroenterol. 1993;88(11):18421849.

25. Hay JA, Lyubashevsky E, Elashoff J, Maldonado L, Weingarten SR, Ellrodt AG. Upper gastrointestinal hemorrhage clinical--guideline determining the optimal hospital length of stay. Am J Med. 1996;100(3):313-322.

26. Atkinson RJ, Hurlstone DP. Usefulness of prognostic indices in upper gastrointestinal bleeding. Best Pract Res Clin Gastroenterol. 2008;22(2):233-242.

27. Enns RA, Gagnon YM, Barkun AN, Armstrong D, Gregor JC, Fedorak RN. Validation of the Rockall scoring system for outcomes from non-variceal upper gastrointestinal bleeding in a Canadian setting. World J Gastroenterol. 2006;12(48):7779-7785.

28. Chen IC, Hung MS, Chiu TF, Chen JC, Hsiao CT. Risk 
scoring systems to predict need for clinical intervention for patients with nonvariceal upper gastrointestinal tract bleeding. Am J Emerg Med. 2007;25(7):774-779.

29. Tham TC, James C, Kelly M. Predicting outcome of acute non-variceal upper gastrointestinal haemorrhage without endoscopy using the clinical Rockall Score.
Postgrad Med J. 2006;82(973):757-759.

30. Masaoka T, Suzuki H, Hori S, Aikawa N, Hibi T. Blatchford scoring system is a useful scoring system for detecting patients with upper gastrointestinal bleeding who do not need endoscopic intervention. J Gastroenterol Hepatol. 2007;22(9):1404-1408. 